\title{
Diversity and Inclusion at East Tennessee State University's Archives of Appalachia
}

Laura E. Smith, East Tennessee State University, USA, University of Tennessee, Knoxville, USA

\begin{abstract}
As East Tennessee State University's (ETSU) Archives of Appalachia approaches its fortieth anniversary, it aims to renew itself as an archive of the twenty-first century through development of a new strategic plan and mission. Diversity and inclusion are a committed part of ETSU's mission to regional stewardship and the Archives seeks to become a more diversified cultural heritage repository and culturally competent workplace. This article applies a top-down approach to understanding diversity- and inclusion-related responses at both the university and department levels to assess current and potential diversity and inclusion initiatives. A selected analysis using the Strategic Diversity Manifesto framework juxtaposes the Archives' diversity and inclusion responses for its local/regional communities and LGBTQ communities. Consequently, the article reports on goals and actions the Archives can take to become a more engaged member of its diverse communities.
\end{abstract}

Keywords: archives; community engagement; cultural heritage; diversity and inclusion; organizational development

Publication Type: research article

O n September 1, 1978, East Tennessee State University's (ETSU) Archives of Appalachia ${ }^{1}$ opened its doors to the public with the "primary purpose . . . to identify, collect, and preserve those materials that document the history and development of the Southern Appalachian region" (Archives of Appalachia, 1979, p. 1). ${ }^{2}$ Established in conjunction with the Institute for Appalachian Affairs, a core of the newly founded Archives of Appalachia was ETSU's Oral History Archives, created by two English professors, Dr. Thomas G. Burton and Dr. Ambrose N. Manning. Burton and Manning-and their students-had traversed east Tennessee and western North Carolina in the late 1960s and early 1970s to capture regional Appalachian history, folklore, music, and customs. The Archives of Appalachia's inaugural newsletter reveals the Archives pursued additional collections by seeking "papers of those persons or organizations active at the grassroots or local level in economic, political, and/or cultural activities" with the "hopes to attract the records of regional labor organizations, businesses, artist colonies and guides, and self-help societies" (Archives of Appalachia, 1979, p. 1). Papers of "individuals-both leaders and rank-and-file-who .... participated in some uniquely Appalachian activity" were also sought (Archives of Appalachia, 1979, p. 1).

Today, the Archives of Appalachia is part of the Center for Appalachian Studies and Services, a Tennessee Distinguished Center of Excellence, under the College of Arts and Sciences. The Archives has grown to include over 9,000 linear feet of archival material made up from over 800 collections (Archives of Appalachia, 2017a, p. 12). Collection strengths include, but are not limited to, material on agriculture and land use, economic conditions and development, environment, folklore, local history and memoirs, music, politics, railroads, religion, social 
justice, travel and tourism, and women (Archives of Appalachia, 2017b, p. 3). Collections are most frequently used to support the curriculum of ETSU and local cultural heritage research projects, but the Archives welcomes and assists researchers from across the Appalachian region and around the world.

As the Archives nears its fortieth anniversary, it is undergoing a process of organizational assessment and development that will result in a new mission statement and strategic plan. Archives staff are working to identify initiatives that will help meet goals of twenty-first century researchers, are reflective of the diversity of the Appalachian region and ETSU, and promote inclusion within the university and its broader communities. As a member of the Archives' staff, the author works to ensure that the Archives' accessibility policies and services provide a welcoming environment to all researchers. She supports ETSU faculty, staff, and students, as well as the public, with their research endeavors. However, as part of this work, she sees how standard archival practices, policies, and resource tools can sometimes be limiting or challenging for first-time or seasoned researchers. The author has become familiar with the disparity of archival collections relating to underrepresented or marginalized populations because materials are considered non-existent, under-documented, or hidden (located in collections, but inaccurately titled or inadequately described). While she knows these challenges and disparities are, unfortunately, common in archives and other special collections repositories, she believes there are steps archivists can take to ensure diversity and inclusion are an integral part of archival repositories in their capacities as cultural heritage organizations and as workplaces.

This article examines diversity and inclusion at ETSU's Archives of Appalachia in response to a diversifying university and regional locality, and the ongoing professional discussion within the archival field. Application of the Strategic Diversity Manifesto (SDM) framework (Mehra \& Davis, 2015), has proved most helpful in assisting the Archives of Appalachia with identifying diversityand inclusion-related information policy and planning, connections, and information sources available at ETSU. As the Archives of Appalachia seeks to strengthen its role within ETSU's campus-wide diversity initiatives, evaluate and "address gaps in embracing diversity," and move towards "representing such information in [its] strategic planning and web documentations," the SDM pushes the Archives to consider additional resources, actions, and networking opportunities with its communities and within the archival profession (Mehra \& Davis, 2015, p. 18). This article documents the Archives' ongoing journey with the SDM framework.

\section{Literature Review}

The discussion of diversity within the archival profession has varied over the last decade. Elizabeth Adkins, in her presidential address at the 2007 Society of American Archivists (SAA) Annual Meeting in Chicago, called for consideration of diversity within the profession, diversity within SAA, and diversity in the historical record. She argued that SAA should move forward with initiatives such as:

- outreach to minority studies programs on college and university campuses to further research and "introduce students to the profession;"

- encouragement of minority archivists to become archival educators;

- renewed efforts for public awareness, especially to engage "underdocumented and underrepresented ethnic groups as a strategy for raising interest in the profession and highlighting the need for documenting these groups" (Adkins, 2008, pp. 41-44). 
Discourse on diversity in the profession continued in articles such as Mario H. Ramirez's (2015) "Being Assumed Not to Be: A Critique of Whiteness as an Archival Imperative" and Alex H. Poole's (2017) "Pinkett's Charges: Recruiting, Retaining, and Mentoring Archivists of Color in the TwentyFirst Century."3 Ramirez's critique was a strong response to Mark Greene's "A Critique of Social Justice as an Archival Imperative: What Is It We're Doing That's All That Important?" published in the Fall/Winter 2013 issue of The American Archivist. Ramirez (2015) wrote, "Despite rolling out the proverbial welcome mat for 'diversity' through some of its programs and policies, and exhibiting an enthusiastic tolerance for difference, representative organizations in the United States, such as the Society of American Archivists, continue to fail to experience structural changes that would shift nearly exclusive directional and policy-making power away from the hands of whites" (p. 348). Poole (2017) furthered the critique of diversity in the profession via qualitative research on the experiences of Harold T. Pinkett Minority Student Award recipients. His research produced findings on "undergraduate experiences, information and library science, the archives field, mentoring relationships, diversity at work, the Society of American Archivists, and lessons learned and recommendations to archivists of color" (Poole, 2017, p. 110).

In addition to discussion of diversity in the profession and SAA, archivists have remained engaged in exploration of methods to diversify the historical record through community engagement as seen in "Saving All the Freaks on the Life Raft: Blending Documentation Strategy with Community Engagement to Build a Local Music Archives" by Caroline Daniels, Heather Fox, Sarah-Jane Poindexter, and Elizabeth Reilly (2015). The authors reported on collection development efforts based on "the professional discussion around documentation strategy, and concerns with community archives and the appropriate role of institutions in efforts to preserve community history" (Daniels, Fox, Poindexter, \& Reilly, 2015, p. 241). Likewise, "Documenting Regional Latino Arts and Culture: Case Studies for a Collaborative, Community-Oriented Approach" by Tracy B. Grimm and Chon A. Noriega (2013) addressed documentation challenges through case studies to better "identif[y] and preserv[e] the archives of underrepresented groups and topics [to] represent better the American experience" (p. 96).

More recently, literature has expanded to address diversity and inclusion in "mainstream archives" and "community archives" (Greene, 2014, p. 25). Mark Greene (2014), a well- regarded leader in the archival field for his work on archival appraisal, shared his personal reflections in a thought-provoking essay titled, "Into the Deep End: One Archivist's Struggles with Diversity, Community, Collaboration and Their Implications for the Profession," published in Through the Archival Looking Glass: A Reader on Diversity and Inclusion. Greene (2014) concluded through his experience: "improving not only the documentation of, but also the overall engagement with, multicultural communities is both an obligation and necessity for mainstream as well as community archives" (p. 47). Chris Taylor (2017) gave an insightful keynote address at the 2016 Joint Annual Meeting of the Council of State Archivists and the Society of American Archivists called "Getting Our House in Order: Moving from Diversity to Inclusion." He spoke of his experience and perspective as a "diversity and inclusion practitioner who happens to work for a historical society," arguing that repositories that focus on inclusion internally are able to better engage their external communities (Taylor, 2017, p. 20). Others have contributed to the discussion through research. For example, Michelle Caswell, Marika Cifor, and Mario H. Ramirez (2016) looked at a series of responses to the community-based South Asian American Digital Archive (SAADA) in "'To Suddenly Discover Yourself Existing': Uncovering the Impact of Community Archives" to study how community archives contribute to "representational belonging" by "counter[ing] the symbolic annihilation of the community" (p. 56). They described community archives as "parts of larger social and political movements whereby groups who have

The International Journal of Information, Diversity, \& Inclusion, 2(4), 2018 ISSN 2574-3430, publish.lib.umd.edu/IJIDI/ 
been ignored, misrepresented, or marginalized by mainstream archival repositories launch their own archival projects as means of self-representation, identity construction, and empowerment" (Caswell, Cifor, \& Ramirez, 2016, p. 61). The authors juxtaposed community and mainstream archives by describing community archives "as grassroots alternatives to mainstream repositories through which communities can make collective decisions about what is of enduring value to them, shape collective memory of their own pasts, and control the means through which stories about their past are constructed" (Caswell, Cifor, \& Ramirez, 2016, p. 61).

While there may be limited agreement on how to best move forward with diversity and inclusion practices, archivists have much to learn from each other and about themselves as they seek ways to increase inclusivity in repositories and workplaces. Whether an archive is considered "mainstream," "community," or perhaps somewhere in-between, the archival profession calls on archivists to address and act on issues of diversity and inclusion. As Chris Taylor (2017) said, "While we do need to identify communities of interest . . . the common denominator in all of our functions and activities that emphasize various communities is us. . . Regardless of what community or dimension of difference we emphasize, the staff, the leadership, and the culture of our organizations all shape how we do our external work" (p. 21).

\section{The Community Context}

The Archives of Appalachia at ETSU is located in Johnson City, Tennessee, a city in South Central Appalachia with a population of 63,152 (U.S. Census Bureau, 2010). M. Denis Peterson (2018), City Manager, describes Johnson City as a "goal-oriented, high-energy, family-centered city with diverse economic component . . . led by healthcare, education, and an entrepreneurial spirit" (para. 1). Recent city projects that promote community engagement include sidewalk and trail construction to connect neighborhoods, downtown business development and structural improvements, and construction of a new pavilion and common space (City of Johnson City, 2017).

ETSU leadership works closely with Johnson City and the broader northeast Tennessee community to further economic and cultural development, as part of its mission to "[Develop] a world-class environment to enhance student success and improve the quality of life in the region and beyond" (ETSU, 2017b, para. 1). As part of ETSU's "Stewardship of Place," the university provides management and/or services for an Innovation Laboratory, the Johnson City Community Health Center, Center for Prescription Drug Abuse Prevention and Treatment, and the Volunteer Income Tax Program. The University's Quillen College of Medicine provides a $\$ 500$ million annual economic impact on the region (Noland, 2016, pp. 68-70). In addition, ETSU will oversee $\$ 152$ million in construction projects from 2017-2022, which includes the construction of the Martin Center for the Arts. The Martin Center for the Arts includes funding from the state and university, as well as private donations and funds from Johnson City (Brooks, 2017).

In addition to being located in an evolving, rapidly changing local environment, ETSU is embracing its own diversity and changes. In 2016, the university opened its first and long-awaited Multicultural Center to "provide students of all cultural backgrounds with educational support programs and services, a place to meet, opportunities to talk about issues that affect their lives, and more" (ETSU, Office of University Relations, 2016, para. 3). The Multicultural Center resulted from a series of meetings by the University's Committee for 125, "a group of campus and regional leaders who led a strategic planning and visioning effort following ETSU's centennial year (2011)" (ETSU, Office of University Relations, 2016, para. 8). The Committee identified the need for ETSU to become "recognized nationally as a student-centered university

The International Journal of Information, Diversity, \& Inclusion, 2(4), 2018

ISSN 2574-3430, publish.lib.umd.edu/IJIDI/ 
fostering a transformative educational experience that affirms the value and richness for diversity" (ETSU, Office of University Relations, 2016, para. 9).

Engaged university, local, and regional communities provide great opportunities for the Archives of Appalachia as it continues its mission to "to collect and preserve records of enduring value that document Appalachia's history and cultural heritage and make those records accessible for use by scholars, educators, students, and the general public" (Archives of Appalachia, 2018). For example, over the past several years, the Archives has supported its regional community by providing images for projects such as the Tweetsie Trail, the longest rails-to-trails project in Tennessee, and has hosted community groups such as the 2013 Reunion of Women Coal Miners (Archives of Appalachia, 2017a).

The Archives' 2016 SWOT (Strengths, Weaknesses, Opportunities, and Threats) Analysis includes several topics, which, if addressed, have the potential to strengthen and promote diversity and inclusion (Archives of Appalachia, 2016). Table 1 identifies and describes the four topics with the strongest relation to diversity and inclusion as location, advocacy, community, and professional development.

Table 1. Archives of Appalachia and Diversity

\begin{tabular}{|c|c|}
\hline Area & Description \\
\hline Location & $\begin{array}{l}\text { In what ways can the Archives be involved or draw on its geographic and } \\
\text { cultural environment to advance its commitment as a culturally competent } \\
\text { workplace and cultural heritage organization? }\end{array}$ \\
\hline Advocacy & $\begin{array}{l}\text { How can the Archives strengthen external and internal relationships with } \\
\text { community stakeholders and develop partnerships that help promote } \\
\text { diversity and inclusion? }\end{array}$ \\
\hline Community & $\begin{array}{l}\text { How is the university and regional community changing? How does the } \\
\text { Archives define itself as a "twenty-first century archive" in terms of } \\
\text { Appalachia's diversity (White \& Gilliland, 2010)? }\end{array}$ \\
\hline $\begin{array}{l}\text { Professional } \\
\text { Development }\end{array}$ & $\begin{array}{l}\text { How can the Archives connect with and learn from similar repositories } \\
\text { through professional organizations such as the Society of American Archivists, } \\
\text { the American Library Association, or the Association of College and Research } \\
\text { Libraries to "get its own house in order" and create an inclusive and culturally } \\
\text { competent workplace (Taylor, 2017)? What steps can professional staff take } \\
\text { to increase cultural competency? }\end{array}$ \\
\hline
\end{tabular}

Note. This table details four areas of the Archives' 2016 SWOT Analysis that most strongly align with diversity and inclusion initiatives.

In order to move forward with the Archives' need to embrace diversity and inclusion as a cultural heritage organization that forms an important part of ETSU, a comprehensive analysis of existing diversity responses is required. 


\section{Strategic Diversity Manifesto: A Brief Analysis}

Designed "as a progressive manifesto for public libraries in the $21^{\text {st }}$ century to address gaps in embracing diversity," Bharat Mehra's and Rebecca Davis' (2015) SDM consists of three "components:" the "Who," the "What," and the "How" (p. 18). Table 2 is an abbreviated representation of the SDM instrument (Mehra \& Davis, 2015, pp. 19-22).

Table 2. Abbreviated SDM Instrument

\begin{tabular}{|c|c|c|}
\hline Identifier & Name & Recording of the "How" with Specific Evidence \\
\hline A & \multicolumn{2}{|c|}{$\begin{array}{l}\text { "Who": Identification of a characteristic/trait, such as abilities or } \\
\text { (dis)abilities }\end{array}$} \\
\hline A.A & \multicolumn{2}{|c|}{ "What": Information Policy and Planning } \\
\hline A.A. 1 & Diversity Committee & $\begin{array}{l}\text { "How": identification of committee(s) and/or } \\
\text { designated individuals }\end{array}$ \\
\hline A.A.2 & Diversity Representation & $\begin{array}{l}\text { "How": identification of diversity statements } \\
\text { and/or wording in planning and policy documents }\end{array}$ \\
\hline A.B & \multicolumn{2}{|c|}{ “What": Connections (Internal \& External) } \\
\hline A.B.1 & $\begin{array}{l}\text { Internal centers and } \\
\text { organizations }\end{array}$ & $\begin{array}{l}\text { "How": identification of relevant centers and } \\
\text { organizations }\end{array}$ \\
\hline A.B.2 & $\begin{array}{l}\text { External community } \\
\text { engagement }\end{array}$ & $\begin{array}{l}\text { "How": identification of community centers and } \\
\text { organizations outside agency }\end{array}$ \\
\hline A.B.3 & $\begin{array}{l}\text { News and upcoming } \\
\text { events }\end{array}$ & $\begin{array}{l}\text { "How": identification of news and events that } \\
\text { occurred within one year }\end{array}$ \\
\hline A.C & \multicolumn{2}{|c|}{ "What": Information Sources } \\
\hline A.C. 1 & Collections & $\begin{array}{l}\text { "How": identification of print, electronic, or } \\
\text { digital collections }\end{array}$ \\
\hline A.C.2 & Resources & $\begin{array}{l}\text { "How": identification of indexes, guides, } \\
\text { funding, and staff }\end{array}$ \\
\hline
\end{tabular}

Note. This table shows the "Who," "What," and "How" SDM components (Mehra \& Davis, 2015, pp. 19-22). Of note, the Mehra and Davis (2015) SDM instrument featured the "What" items as follows: Information Sources, Information Policy and Planning, and Connections (Internal \& External). To reflect how the SDM was applied to the Archives of Appalachia, and for consistency within this article, the sections have been rearranged as shown.

The "Who" asks libraries-or other organizations utilizing the SDM-to identify diverse user groups within their communities in relation to efforts for improving connections to those groups. Suggested characteristics/traits include: abilities or (dis)abilities; age; educational differences; gender concerns; international; LGBTQ; local/regional; racial/ethnic categories; and religion 
(Mehra \& Davis, 2015, pp. 19-20). However, the authors are quick to note that crossclassification or additional categories should be developed to reflect the uniqueness of community needs. The "What" component includes three main categories: information policy and planning, connections (internal and external), and information sources. Libraries, or other organizations, evaluate each of the "What" in relation to the "Who." Documentation of the library's responses for the "What" of the groups is recorded as the "How."

\section{Methodology}

Information for the SDM was collected from a variety of public and internal documentation at ETSU. Review of ETSU's organizational structure allowed for identification of colleges, departments, centers, and committees that support groups with characteristics/traits identified in the SDM. ${ }^{4}$ Searches conducted on the ETSU website (http://www.etsu.edu) revealed strategic planning documentation and additional diversity-related committees and organizations. The author's familiarity with ETSU as an employee was of benefit while conducting online searches and identifying resources. Her employee status allowed for the retrieval and utilization of the Archives' internal documentation, such as policy drafts not yet publicly available. Responses for local/regional and LGBTQ communities emerged as the strongest examples as a fully developed response (local/regional) and a response where the Archives could focus future diversity and inclusion efforts (LGBTQ). Subsequently, the two responses are selectively featured in this article.

\section{Diversity Responses at the Archives of Appalachia}

As a cultural heritage organization located at a public, state university, ETSU's Archives of Appalachia is part of an academic community that provides numerous resources regarding diversity, including staff, programming, research collections, and scholarship. An adaptation of the SDM (Mehra \& Davis, 2015) applies a mix of those resources to: identify ETSU's diversityrelated resources currently available on campus; analyze for shared goals, initiatives, and partnerships across campus that have yet to be realized; and recognize the current diversityrelated impact of the Archives and ETSU with external communities. The author applied the SDM in the context of the Archives of Appalachia in the spring of 2018. Her adaptation of the framework included all of the initial representative "Who" characteristics/traits Mehra and Davis (2015) identified "to demarcate the users, patrons, customers, clients, or audiences . . ." in a selectively encompassing manner (p. 19). This allowed the author to develop for the Archives insights related to a centralized resource reflective of its current diversity resources and bring awareness to areas of improvement in all aspects of diversity and inclusion. However, future applications may include modified categories or "cross classification" (Mehra \& Davis, 2015, p. 20). The author also adopted all the "What" aspects of the SDM in its description of the various types of information offerings available at various organizations and agencies. Table 3 provides a checklist assessment of the "Who" and "What" elements of the SDM as applied in the context of the Archives of Appalachia and is indicative of the existing diversity responses at ETSU. The checks and crosses are based on an occurrence of the relevant information on the agency's websites, databases, and policies. 
Table 3. Checklist assessment of the SDM applied to the Archives of Appalachia at ETSU

\begin{tabular}{l|llllllll}
\hline "Who" & "What" & $\Rightarrow$ & & & & & \\
\hline & A1 & A2 & B1 & B2 & B3 & C1 & C2 & Total \\
\hline A & $\checkmark$ & $\checkmark$ & $\checkmark$ & $\checkmark$ & $\checkmark$ & $\checkmark$ & $\checkmark$ & $7 / 7$ \\
B & $\checkmark$ & $\checkmark$ & $\checkmark$ & $\checkmark$ & $\checkmark$ & $\checkmark$ & $\checkmark$ & $7 / 7$ \\
C & $\times$ & $\checkmark$ & $\checkmark$ & $\checkmark$ & $\checkmark$ & $\checkmark$ & $\checkmark$ & $6 / 7$ \\
D & $\checkmark$ & $\checkmark$ & $\checkmark$ & $\checkmark$ & $\checkmark$ & $\checkmark$ & $\checkmark$ & $7 / 7$ \\
E & $\checkmark$ & $\checkmark$ & $\checkmark$ & $\checkmark$ & $\checkmark$ & $\checkmark$ & $\checkmark$ & $7 / 7$ \\
F & $\checkmark$ & $\checkmark$ & $\checkmark$ & $\checkmark$ & $\checkmark$ & $\checkmark$ & $\checkmark$ & $7 / 7$ \\
G & $\checkmark$ & $\checkmark$ & $\checkmark$ & $\checkmark$ & $\checkmark$ & $\checkmark$ & $\checkmark$ & $7 / 7$ \\
H & $\checkmark$ & $\checkmark$ & $\checkmark$ & $\checkmark$ & $\checkmark$ & $\checkmark$ & $\checkmark$ & $7 / 7$ \\
I & $\times$ & $\checkmark$ & $\checkmark$ & $\checkmark$ & $\checkmark$ & $\checkmark$ & $\checkmark$ & $6 / 7$ \\
\hline
\end{tabular}

KEY

$\mathrm{A}=$ Abilities (or disabilities) $\mathrm{B}=$ Age $\mathrm{C}=$ Educational differences; $\mathrm{D}=$ Gender concerns; $\mathrm{E}=$ International; $\mathrm{F}=\mathrm{LGBTQ} ; \mathrm{G}=$ Local/Regional; $\mathrm{H}$ = Racial/Ethnic categories; I = Religion

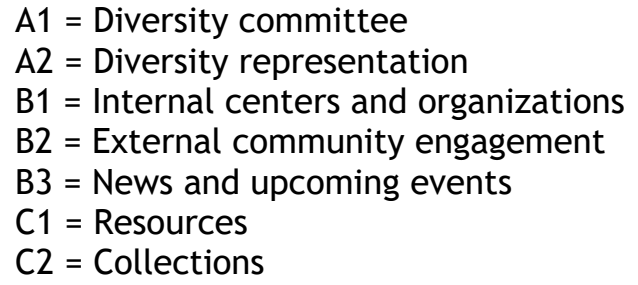

Note. This table provides an initial overview of the diversity responses for the characteristics/traits defined by Mehra and Davis (2015).

The author applied the SDM in the context of the Archives of Appalachia as a department of ETSU since its current and potential diversity-related services and resources are contingent upon understanding the roles and responsibilities of the Archives in relationship to its parent organizations. Figure 1 illustrates the Archives' place in ETSU's organizational structure.

Unsurprisingly, the author found that the SDM's main resource sections, Information Policy and Planning, Connections (Internal and External), and Information Sources largely correlate with the organizational structure. This correlation is also depicted in Figure 1. Taking this realization into account, a systematic analysis of the SDM requires a top-down approach for a sequence of Information Policy and Planning-ETSU, Connections-College of Arts and Sciences and Center for Appalachian Studies and Services, and Information Sources-Archives of Appalachia. 


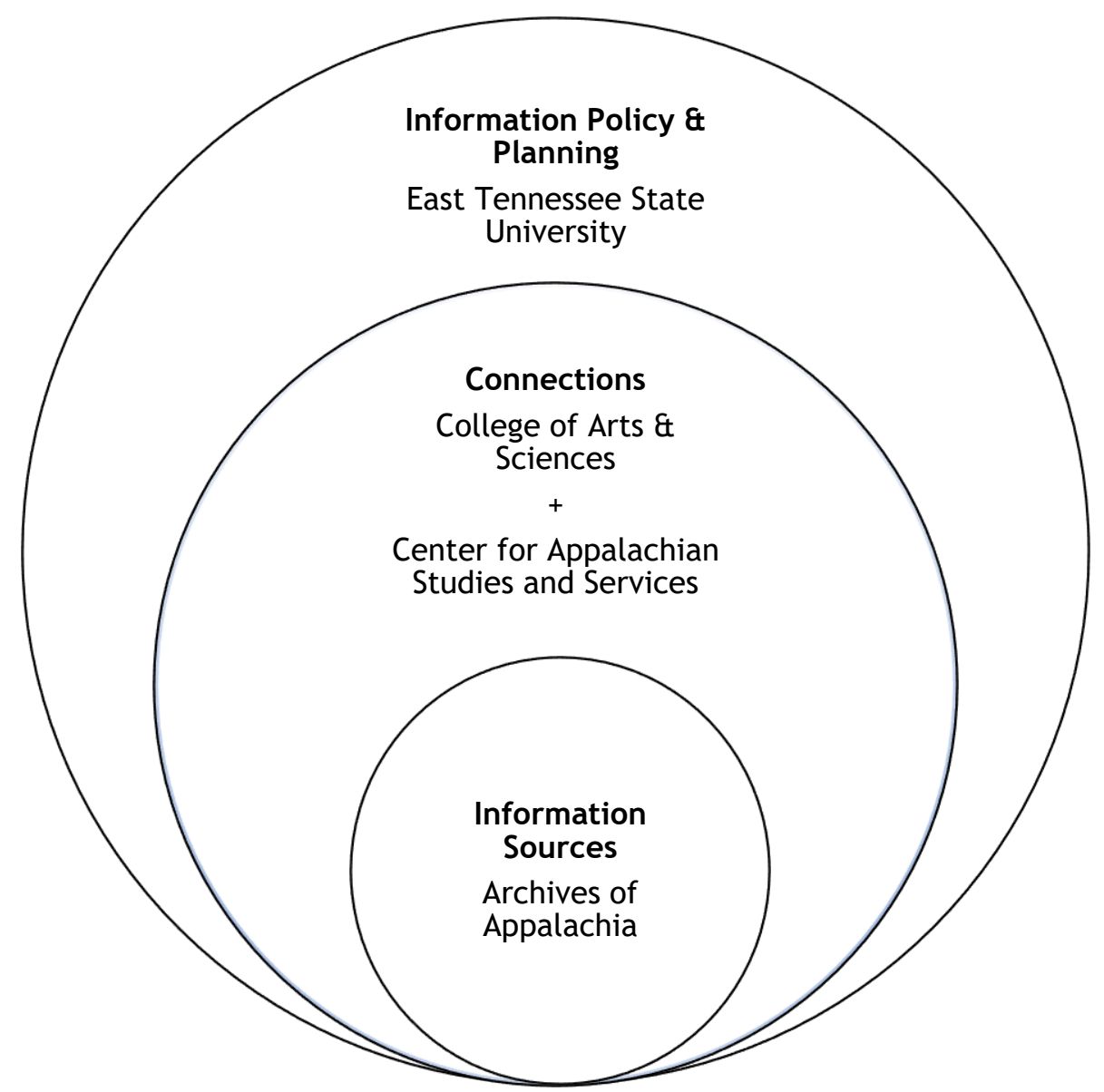

Figure 1: The Archives of Appalachia, organizational structure. This figure illustrates the organizational relationships between the Archives of Appalachia, Center for Appalachian Studies and Services, College of Arts \& Sciences, and ETSU.

\section{Information Policy and Planning-ETSU}

Acting on its mission and values that "PEOPLE come first, are treated with dignity and respect, and are encouraged to achieve their full potential" and "DIVERSITY of people and thought is respected," ETSU has numerous internal offices, organizations, centers, committees, and programs that focus on campus diversity, including, but not limited to: the Office of Equity and Diversity, Office of Multicultural Affairs, ETSU Safe Zone (LGBTQ Campus Allies), Language and Cultural Resource Center, ETSU Disability Services, and International Programs and Services (ETSU, 2017b, para. 2). Selected committees include the ETSU Commission for Women Standing Committee, International Advisory Council, ETSU Disability Issues Standing Committee, ETSU Accessibility Task Force Advisory Committee, Service-Learning/Community and Public Service Standing Committee, and Race Relations Standing Committee (under review for restructuring in 2018) (ETSU, University Governance, 2018). All of these diversity-related offices, organizations, centers, committees, and programs work together to establish, review, and update policies and strategic plans to create a respectful, diverse community. As such, ETSU offers a variety of information resources and programming throughout the year, many of which include opportunities for the public to attend. 
ETSU's Strategic Plan for 2016-2026 not only affirms its mission and values, but also identifies "Ensuring the diversity and inclusion of people and ideas" as one of its "six major areas of focus" that will "provide a framework for planning and decision-making" (ETSU, 2017a, p. 3). Included in the plan are goals to establish a diversity task force and a "focus on defining diversity and defining inclusion and expanding our view of diversity beyond race or nationality . . . in areas including students, faculty/staff, student life, and community around ETSU" (ETSU, 2017a, pp. 8-9). In addition, ETSU set goals to become an Insight into Diversity: Higher Education Excellence in Diversity institution and a recipient of the Carnegie Community Engagement Classification from the Carnegie Foundation by 2026 (ETSU, 2017a, p. 11).

\section{Connections (Internal and External)-Center for Appalachian Studies \& Services and College of Arts and Sciences}

The Center for Appalachian Studies \& Services, of which the Archives of Appalachia is a part, is a Tennessee Distinguished Center of Excellence. The Center dates back to 1984 when the General Assembly and the Governor of Tennessee established the Center of Excellence program, "designed to build upon the research strengths of the campuses of Tennessee Board of Regents and University of Tennessee" by "focus[ing] on the capabilities of public higher education to serve the people of Tennessee by expanding the state's research base; thereby, increasing its national and international stature and its economic competitiveness" (Tennessee Higher Education Commission, 2018, para. 1). The Center's Regional Resource Institute (RRI) is defined as, "the administrative arm of the Center . .. [that] facilitates partnerships with ETSU academic units . . . and with community organizations . . . to promote research about and service to the Appalachian region . . . by administer[ing] long-term grant projects (Appalachian Teaching Project and Governor's School for the Scientific Exploration of Tennessee Heritage) and special grant projects....For 33 years, the RRI has also published Now \& Then: The Appalachian Magazine" (Center for Appalachian Studies and Services, 2018a, para. 1).

The Archives' sister organization, the Reece Museum, is also part of the Center for Appalachian Studies \& Services. Open to the public, the Reece Museum develops exhibits in addition to hosting traveling exhibits, which promote diversity and reach out to underrepresented communities. Recent exhibits included Finite Disappointment/Infinite Hope (January 17 - March 23, 2018) and A New Subjectivity (October 24 - December 2017). Finite Disappointment/Infinite Hope was "presented in tribute to and commemoration of Rev. Martin Luther King Jr. and the ongoing quest for justice and racial equality" and "feature[d] the work of contemporary Washington, D.C.-based photographer and ETSU alumnus Gediyon Kifle" with "an innovative and educational retelling of historical narratives from an artist's perspective" (ETSU, Office of University Relations, 2018, para. 1-2). A New Subjectivity was the first time the Reece Museum led tours for the low-vision and blind community and included "verbal descriptions of the works and hand-held tactile boards of the paintings" (ETSU, Office of University Relations, 2017, para. 3).

As part of the College of Arts \& Sciences, the Center for Appalachian Studies \& Services and its units, the Archives of Appalachia and Reece Museum, work closely with academic departments. While the Center collaborates with a variety of departments, the closest subject-related department is the Department of Appalachian Studies. According to Dr. Ron Roach (2018), Chair of the Department of Appalachian Studies and Director of the Center for Appalachian Studies \& Services, "The Department of Appalachian Studies at ETSU is the only academic department of its kind in the United States. . . .Though one third of the state of Tennessee falls within the Appalachian region, ETSU is the only fouryear institution in the state whose mission is to serve the Appalachian region" and its "location in the heart of Appalachia positions it to capitalize on the region as a laboratory for research, service learning, active community work, and building collections" (para. 1). The Department of Appalachian

The International Journal of Information, Diversity, \& Inclusion, 2(4), 2018

ISSN 2574-3430, publish.lib.umd.edu/IJIDI/ 
Studies offers undergraduate minors in Appalachian Studies, Environmental Studies, and Appalachian, Scottish, and Irish Studies; a Bachelor of Arts in Bluegrass, Old Time, and Country Music; and a Master of Arts in Appalachian Studies. While the department offers numerous courses, of particular note is the course Documenting Community Traditions, a "cross-disciplinary seminar [that] involves fieldwork in Appalachian communities seeking cultural or economic sustainability through the development of their traditional and contemporary assets" (Department of Appalachian Studies, ETSU, n.d., "Course Descriptions," para. 8). Focus areas have included: Marketing the Craftspeople and Artists of Northeast Tennessee (Herrin, 2009); Sustainable Agriculture in Northeast Tennessee (Herrin, 2011); Railroad History and Cultural Heritage Tourism in Northeast Tennessee (Herrin, 2015); and Rocky Fork State Park: Linking Natural and Economic Resources Through Oral Histories and Community Engagement (Noland, 2017). Documenting Community Traditions students connect with individuals in the regional community to capture oral histories and work with businesses and organizations to help them realize paths toward sustainability. They present their work as part of the Appalachian Teaching Project, an Appalachian Regional Commission sponsored program that "engages students and regional citizens in posing answers to the question, 'How can we build a sustainable future for Appalachian communities?" (Center for Appalachian Studies and Services, 2018b, para. 1). The coursework is subsequently deposited in the Archives of Appalachia for preservation and future research.

\section{Information Sources-Archives of Appalachia}

The Archives of Appalachia identifies its designated communities as ETSU "students, faculty, staff, administrators, and alumni; scholars and educators of Appalachian history and culture; cultural and educational organizations located in the Appalachian region; and the general public" (Archives of Appalachia, 2017b, p. 2). These communities determine and shape the Archives' collection priorities and educational resources.

Collection Development. The Archives uses the following geographic guidelines when determining collection acquisition: "Archival and printed materials pertaining to south-central Appalachia, particularly northeast Tennessee and contiguous counties in eastern Kentucky, southwest Virginia, and western North Carolina, are acquired . . . ; Archival and printed materials pertaining to central and north-central Appalachia which significantly support the Archives' subject strengths are selectively acquired ... ; Printed materials pertaining to northern and southern Appalachia which provide regional context are selectively acquired ..." (Archives of Appalachia, 2017b, p. 3). The Archives of Appalachia "provides the widest possible access to its collections on equal terms for the purposes of study, research, education, artistic creativity, and the public good" (Archives of Appalachia, 2017b, p. 1). Collection guides are publicly accessible through the Archives' online database (http://archives.etsu.edu). Published print materials held in the Archives are accessible through the library catalog (http://libraries.etsu.edu). Although collection guides and catalogs are available to the public, identifying diversity in the Archives' collections proves challenging. The author has observed that continued engagement and research with collections by Archives staff and researchers has shown that often material has been unidentified or mislabeled, thus further underrepresenting underrepresented communities.

Educational and Community Resources. Over the past four years, the Archives has engaged with nearly 20,000 users through research visits, distance access (phone and e-mail services), and social media. The Archives hosts diverse community organizations for tours and presentations and ensures an accessible environment for all visitors (Archives of Appalachia, 2017a, p. 3). Groups come from a variety of backgrounds, including: secondary school students; Upward Bound students; higher

The International Journal of Information, Diversity, \& Inclusion, 2(4), 2018

ISSN 2574-3430, publish.lib.umd.edu/IJIDI/ 
education students (including non-ETSU); community/civic organizations; business groups; senior center groups; history/genealogy organizations; religious groups; travel groups; and women coal miners. In 2015, the Archives implemented a Community Partnership policy, which strengthens its support of the regional community by providing material at no cost for educational community events and programs (Archives of Appalachia, 2015).

\section{Analysis: Local/Regional and LGBTQ at the Archives of Appalachia}

The following section includes selected analysis and responses developed for those who fall within the "local/regional" and "LGBTQ" categories, two of the "Who" characteristic/trait designations according to the SDM. Mehra and Davis (2015) define local/regional as "A focus on the needs of people of local, regional, and other geographic distributions in relation to a sense of place perceived by users related to the location of the agency in the minds and hearts of the user" (p. 19). LGBTQ refers to lesbian, gay, bisexual, transgender, or queer individuals. Featuring these two responses provides a focused look at a fully developed response (local/regional) and a response that indicates great potential for addressing community needs (LGBTQ). Thus far, the diversity response overview has focused on diversity responses that the Archives and Center lead or are a part of at ETSU. These responses are primarily local/regional with some classification with other SDM characteristics/traits. Table 4 shows the SDM application for local/regional.

The Archives makes available information resources on a variety of Appalachian-related subjects through archival collection and library databases (G.C.1, G.C.2). The University's ServiceLearning/Community and Public Service Standing Committee "encourage[s] ETSU students to derive personal value from service-learning opportunities that link education, work/community, and personal development" and "expand[s] service-learning and community and public service efforts (G.A.1)" (ETSU, University Governance, 2015, para. 1). The Center for Appalachian Studies and Services manages the Governor's School for the Scientific Exploration of Tennessee Heritage, which annually brings thirty upper-level high school students to campus for regional field experiences, including working with primary sources from the Archives of Appalachia (G.B.3). The Archives supports research endeavors by ETSU students enrolled in the class Documenting Community Traditions and the Center sponsors them for attendance at the Appalachian Teaching Project Conference (G.B.3).

Table 4. Local/Regional results of the Archives of Appalachia's SDM

\begin{tabular}{lll}
\hline Identifier & Name & Specific Evidence and URL \\
\hline G & Local/Regional & \\
G.A & Information Policy and Planning \\
G.A.1 & Diversity & Service-Learning / Community and Public Service Standing \\
& Committee & $\begin{array}{l}\text { Committee: } \\
\text { https://www.etsu.edu/universitygovernance/governanceco }\end{array}$ \\
& Diversity & mmittees/servicelearning.php \\
G.A.2 & Representation Strategic Diversity Plan: \\
& $\underline{\text { https://www.etsu.edu/equity/strategicplan.php }}$
\end{tabular}

The International Journal of Information, Diversity, \& Inclusion, 2(4), 2018 ISSN 2574-3430, publish.lib.umd.edu/IJIDI/ 
G.B

G.B.1

G.B.2

G.B.3

News and upcoming events

External community engagement

\section{Connections (Internal and External)}

Internal centers The Center for Appalachian Studies and Services: and organizations https://www.etsu.edu/cas/cass/default.php

The Reece Museum:

https://www.etsu.edu/cas/cass/default.php

The Department of Appalachian Studies:

https://www.etsu.edu/cas/das/welcome.php

Equity and Diversity: https://www.etsu.edu/equity/staff.php

ETSU Organizations and Departments supporting the Multicultural Focus: https://www.etsu.edu/equity/links.php

Office of Multicultural Affairs:

https://www.etsu.edu/students/multcult/default.php

The Archives hosts diverse community organizations for tours and presentations and ensures an accessible environment for all visitors. For example, members of local civic, business, and history/genealogy organizations visit the Archives. The Archives occasionally engages with the local community through radio, television, and newspaper interviews (Archives of Appalachia, 2017a).

Governor's School for the Scientific Exploration of Tennessee

Heritage: https: //www.etsu.edu/cas/cass/governors

Appalachian Teaching Project:

https://www.etsu.edu/cas/cass/projects

\section{G.C Information Sources}

G.C.1 Collections Subject strengths of the Archives' collections include:

"Agriculture and land use, Arts and crafts, Economic conditions and development, Environment and society, Folklore, Literature, culture, and identity, Local history and memoirs, Music and dance, Politics and society, Railroads, Religion and culture, Social conditions, social life, and customs, Social justice, Travel and tourism. Women, minorities, and society" (Archives of Appalachia, 2017b, p. 4). The Archives continues to acquire new collections.

The Archives' book collection continues to expand with ongoing acquisitions of both current and historical publications (Archives of Appalachia, 2017b). 
G.C.2 Resources Collection guides are publicly accessible through the Archives'
online database, ArchivesSpace (http://archives.etsu.edu).

Published print materials held in the Archives are accessible through the library catalog (http://libraries.etsu.edu).

Note. This table shows the diversity responses for the Archives of Appalachia's local/regional communities within the SDM framework.

In contrast to the local/regional response, Table 5 reflects the limited archival resources related to the LGBTQ community in Appalachia. Collections (F.C.1), Resources (F.C.2), and External Community Engagement (F.B.2) only indicate that the Archives includes "social conditions, social life, and customs . . . social justice . . . women, minorities, and society" within its collection scope and that all are welcome in the Archives (Archives of Appalachia, 2017b, p. 4). However, whereas the SDM documents limited archival holdings, it reveals ETSU provides institutional support for improving the Archives' responses with strong policies (F.A.2: ETSU Strategic Diversity Plan), planning (F.A.1: SafeZone Allies), and connections (F.B.1: various departments and organizations). The Archives should utilize those institutional resources to improve its departmental response by creating a more inclusive environment with the campus LGBTQ community, and hopefully local and/or regional LGBTQ communities.

Table 5: LGBTQ results of the Archives of Appalachia's SDM

\begin{tabular}{lll}
\hline Identifier & Name & Specific Evidence and URL \\
\hline F & LGBTQ & \\
F.A & Information Policy and Planning \\
F.A.1 & Diversity Committee & $\begin{array}{l}\text { Safe Zone Allies: } \\
\text { https://www.etsu.edu/equity/safezone/allies.php }\end{array}$ \\
F.A.2 & $\begin{array}{l}\text { Diversity } \\
\text { Representation }\end{array}$ & $\begin{array}{l}\text { ETSU Strategic Diversity Plan: } \\
\text { https://www.etsu.edu/equity/strategicplan.php }\end{array}$ \\
F.B & Connections (Internal and External) \\
F.B.1 & $\begin{array}{l}\text { Internal centers and } \\
\text { organizations }\end{array}$ & $\begin{array}{l}\text { ETSU Safe Zone (LGBTQ Campus Allies): } \\
\text { https://www.etsu.edu/equity/safezone/default.php }\end{array}$ \\
& & $\begin{array}{l}\text { Equity and Diversity: } \\
\text { https://www.etsu.edu/equity/staff.php }\end{array}$ \\
& & $\begin{array}{l}\text { Office of Multicultural Affairs: } \\
\text { https://www.etsu.edu/students/multcult }\end{array}$ \\
& $\underline{\text { Idefault.php }}$
\end{tabular}


ETSU Organizations and Departments supporting the Multicultural Focus:

https://www.etsu.edu/equity/links.php
F.B.2 External community The Archives hosts diverse community organizations engagement for tours and presentations and ensures an accessible environment for all visitors. (Archives of Appalachia, 2017a).
F.B.3 News and upcoming Planlt ETSU: https://calendar.etsu.edu events
Office of Multicultural Affairs Events:
https://www.etsu.edu/students/multcult
Idefault.php

\section{F.C Information Sources}

F.C.1 Collections

Subject strengths of the Archives' collections include: social conditions, social life, and customs . . . social justice . . . women, minorities, and society" (Archives of Appalachia, 2017b, p. 4). The Archives continues to acquire new collections.

The Archives' book collection continues to expand with ongoing acquisitions of both current and historical publications (Archives of Appalachia, 2017b).

Database searches for LGBTQ materials reveals few identified LGBTQ information sources.

F.C.2 Resources Collection guides are publicly accessible through the Archives' online database, ArchivesSpace: http://archives.etsu.edu.

Published print materials held in the Archives are accessible through the library catalog:

http: / / libraries.etsu.edu.

Note. This table shows the diversity responses for the Archives of Appalachia's LGBTQ communities within the SDM framework.

Not shown are the individual SDM response tables for abilities or (dis)abilities, age, educational differences, gender concerns, international, racial/ethnic categories, and religion, although Table 3 provides an overview for each. With the exception of specifically identified diversity committees for educational differences and religion, there is some form of information sources, policy and planning, and connections for each characteristic/trait at ETSU. The author suspects that it is possible committees may exist but remain unidentified and/or that many individuals, departments, and organizations are doing work within these areas without a formal committee 
designation. However, it should be noted that the SDM responses overall are similar to the LGBTQ response, and therefore receive the same reaction: the Archives must do more to recognize diversity within its communities and become more inclusive in its practices to better serve its current and potential users.

\section{Moving Forward}

The Society of American Archivist's Core Values Statement (2011) includes a diversity statement that documents a shared, professional ideology among archivists. Contained within the statement are beliefs that archivists should:

- "document and preserve the record of the broadest possible range of individuals, socio-economic groups, governance, and corporate entities;"

- "embrace the importance of identifying, preserving, and working with communities ... whose voices have been overlooked or marginalized;"

- "build connections to underdocumented communities;"

- "accept and encourage a diversity of viewpoints on social, political, and intellectual issues ... both in archival records and among members of the profession;"

- "work actively to achieve a diversified and representative membership in the profession." (para. 4)

This core value statement emphasizes the importance of archives and archivists to a diversified historic and cultural record, community engagement, and archival profession. Undoubtedly, the SDM provides the Archives of Appalachia with a strong start for considering how it could potentially strengthen each of these areas by:

\section{Establishing New Policies and Practices}

As of spring 2018, staff of the Archives of Appalachia and the Center for Appalachian Studies and Services are meeting, discussing, and drafting new mission and vision statements, as well as new strategic plans. The time is right to ensure these new statements and goals reflect and embrace diversity and inclusion. Ongoing and future meetings should incorporate assessment, discussion, and implementation of wording, initiatives, and goals that support diversity and inclusion. Archives and Center staff should discuss and document their experience working with diverse community groups and cultural heritage collections by asking: What work has been done to further diversity and inclusion initiatives? What has worked and what has not? What feedback from the community has been given, or how can that information be obtained?

While the Archives has not yet finalized its strategic plans, its overall purpose to collect, preserve, and make accessible materials of historic and cultural importance to Appalachia and East Tennessee State University remains. In each of these areas, the Archives can take an active role in supporting the university's strategic framework in regards to diversity and inclusion on and off campus. Chris Taylor (2017), chief inclusion officer at the Minnesota Historical Society, said the following while delivering the keynote address at the 2016 Joint 
Annual Meeting of the Council of State Archivists and the Society of American Archivists, "As socially conscious organizations, we need to reach out and invite diverse communities to engage with us. We need to be open to engage on terms that are comfortable for community members, but may not be comfortable for us. It is not fair to broader sectors of society that we only engage with communities that we are comfortable with. It is our responsibility to correct that" (p. 24). With Taylor's words in mind as the Archives continues discussion of its new strategic plan and mission statement, work towards creating a more diversified cultural heritage organization and workplace can begin.

\section{Conducting Community Analyses}

As a regional, public archive located on a university campus, the Archives of Appalachia assists a variety of on-site visitors over the course of the fiscal year (July 1 - June 30). During the summer, the Archives generally sees an increase of non-campus researchers, including locals and out of town visitors, whom the author suspects enjoy easier parking while most of campus enjoys a summer break. However, non-campus visitors frequent the Archives year-round. At the beginning of the fall and spring semesters, the Archives provides archival orientation sessions for a variety of classes. While some instructors only request orientations to provide students with a basic introduction to archives, other instructors also require students to return for research as part of graded assignments. Students with research assignments engage with the Archives throughout the semester. Fall courses requiring an archival orientation are more likely to include introductory classes for a program or degree while spring courses include more specialized or advanced coursework. While this "researcher cycle" will sound familiar to archivists at academic institutions, it is important to note, especially when considering implementing a community analysis aimed toward gathering feedback from all users.

The author is unaware of any previously conducted survey, focus group, or other feedback opportunities provided by the Archives that solely focused on user perception of the Archives and/or how the Archives collects, preserves, and makes accessible materials related to their history, culture, or research interest. The author developed a Community Feedback: Diversity draft survey (Appendix) in hopes of providing the Archives and its community with the following opportunities:

- Strengthen connections between the Archives and its users through feedback on perception of the Archives in comparison to the Archives' current mission;

- Better understand the diversity of the Archives' user community through demographic data capture;

- Develop community networks and provide more diversified public services, including professional assistance to local, community archives.

The Archives of Appalachia's "researcher cycle" requires that staff conduct the Community Feedback: Diversity survey over the course of a full academic year in order to obtain a full capture of the diversity of its summer, fall, and spring users.

\section{Beginning a Diversity Assessment of Collections}

Archives staff should review its collections for increased awareness of material relating to the history and culture of underrepresented groups. Familiarity with collections will allow 
archives staff to provide better services within its communities through development of collection resources, such as subject guides, exhibits, or social media engagement.

\section{Focusing on Community Engagement Alongside Professional and Organizational Development}

The Archives should seek partnerships with community groups and stakeholders both on and off campus to become a stronger cultural heritage resource and repository that serves both ETSU and the broader regional community. In addition to being a cultural heritage organization, the Archives must also evaluate itself as a workplace. Ensuring staff have access to, and the ability to attend, professional development opportunities related to diversity and inclusion is imperative. Chris Taylor (2017) may be correct that "Reaching audiences that have been traditionally under engaged by our organizations will not be successful or sustainable through outreach alone. We must begin to fully embrace inclusion within our organizations, within our fields" (p. 24). The Archives must evaluate how inclusive it is and see itself as part of many communities while being willing to shed "best practices" that have allowed archives to become "privileged institutions that exclude non-dominant culture communities" (Taylor, 2017, p. 26).

\section{Conclusion}

The ongoing commitment to diversity and inclusion by ETSU leadership and the actions pursued by that leadership, from the opening of the campus Multicultural Center to its numerous regional health care, education, and economic partnerships, solidifies ETSU's value to "affirm the contributions of diverse people, cultures, and thought to intellectual, social, and economic development" (ETSU, 2017b, para. 5). The commitment drives the university's numerous academic departments, centers, organizations, and the faculty and staff within, to adapt new practices and initiatives that will "ensur[e] the diversity and inclusion of people and ideas" (ETSU, 2017a, p. 3).

As part of the university system, the Archives of Appalachia benefits from being one unit among many, which allows increased opportunities to share resources, establish internal partnerships, and network with external communities. Utilizing the SDM to assess the status of the Archives has already revealed new possibilities for internal campus connections and partnerships. Through continued assessment of its current practices, collection resources, existing and potential partnerships, and renewed commitment to professional and organizational development that supports diversity and inclusion, the Archives of Appalachia is poised to become an improved cultural heritage repository reflective of the twenty-first century.

\section{Acknowledgements}

I give my greatest appreciation to Dr. Bharat Mehra for all of his help, support, and time in developing and reviewing my paper. I extend this appreciation to Dr. Keren Dali and the reviewers at IJIDI. I would also like to acknowledge my fellow Diversity Leadership in Information Organizations classmates from whom I learned a great deal. Finally, I would like to thank my colleagues at the Archives of Appalachia and Center for Appalachian Studies and Services who listened to me talk about the class, engaged in discussion about diversity and inclusion, and reviewed the article. 


\section{Endnotes}

\footnotetext{
1 The Appalachian Regional Commission defines Appalachia as "a 205,000-square-mile region that follows the spine of the Appalachian Mountains from southern New York to northern Mississippi. It includes all of West Virginia and parts of 12 other states: Alabama, Georgia, Kentucky, Maryland, Mississippi, New York, North Carolina, Ohio, Pennsylvania, South Carolina, Tennessee, and Virginia" and "is home to more than 25 million people" (Appalachian Regional Commission, 2018).

2 The Appalachian Regional Commission recognizes five Appalachian sub regions: Northern, North Central, Central, South Central, and Southern. Southern Appalachia includes the northern sections of Mississippi, Alabama, Georgia, and South Carolina. East Tennessee State University is located in Washington County, Tennessee, presently considered part of the South Central sub region (Appalachian Regional Commission, 2018).

${ }^{3}$ Harold T. Pinkett was the first African-American archivist at the U.S. National Archives (19421979).

${ }^{4}$ ETSU's organizational charts are available at: https://www.etsu.edu/humanres/documents/organizationalstructureweb.pdf\#page=1
}

\section{Appendix}

\section{Community Feedback: Diversity}

Affiliation

o ETSU Student o ETSU Faculty o ETSU Staff o ETSU Alumni o ETSU Visitor o Distant Access Researcher

Gender

o Male o Female

Age

o Under 17 o 17-24 o 25-34 o 35-44 o 45-54 o 55-64 o 65-74 o 75 or older

Ethnicity

o Asian o Black or African American o Hawaiian or Pacific Islander o Hispanic or Latino o American Indian or Alaskan Native o White or Caucasian o Other

Education

o Some High School o High School or GED o Some college o College degree or higher

The Archives \& You

How familiar are you with the Archives of Appalachia's public access and services, including online databases/catalog and research assistance? 
o Not all at o Somewhat not familiar o Neutral o Somewhat familiar o Very familiar

How familiar are you with the Archives of Appalachia collections?

o Not all at o Somewhat not familiar o Neutral o Somewhat familiar o Very familiar

How often do you research at or contact the Archives of Appalachia?

o Monthly o 2-3 times a month o 2-4 times a year o Once a year

The Archives of Appalachia's mission is to:

“. . . support original research, educational engagement, and artistic creativity that promotes an understanding of the Appalachian region. The Archives seeks to collect and preserve those records of enduring value that document Appalachia's history and cultural heritage and make those records accessible for use by scholars, educators, students, and the general public. The Archives particularly seeks records from south-central Appalachia, specifically northeast Tennessee and bordering counties in eastern Kentucky, southwest Virginia, and western North Carolina."

Do you think the Archives fulfills its mission? Please explain.

Does your area of research/interest focus on marginalized or underrepresented communities in Appalachia?

o Yes o No

If yes, please explain your experience researching at the Archives of Appalachia (Ex. What materials did you hope to find? Did you find materials related to your research?).

How can the Archives improve its services to further a welcoming environment?

Thank you for your participation! If you are aware of material that the Archives may be interested in collecting, please contact the Archives at 423.439.4338 or archives@etsu.edu.

\section{References}

Adkins, E. W. (2008). Our journey toward diversity-and a call to (more) action. American Archivist, 71(1), 21-49.

Archives of Appalachia. (1979, March 1). Introducing the Archives of Appalachia. Archives of Appalachia Newsletter, 1(1), 1-2. 
Archives of Appalachia. (2015). Community partnership. Johnson City, TN: East Tennessee State University.

Archives of Appalachia. (2016). Strategic planning \& SWOT analysis. Unpublished internal document.

Archives of Appalachia. (2017a). Archives of Appalachia multi-year annual report. Unpublished manuscript.

Archives of Appalachia. (2017b, March 28). Archives of Appalachia collections policy. Johnson City, TN: East Tennessee State University.

Archives of Appalachia. (2018). Mission: Understanding the Appalachian region. Retrieved from https://www.etsu.edu/cas/cass/archives/mission.php

Brooks, C. (2017, April 6). ETSU to see over $\$ 152$ million of construction in next five years. Johnson City News and Neighbor. Retrieved from http://jcnewsandneighbor.com/etsuto-see-over-152-million-of-construction-in-next-five-years

Caswell, M., Cifor, M., \& Ramirez, M. H. (2016). "To suddenly discover yourself existing": Uncovering the impact of community archives. American Archivist, 79(1), 56-81.

Center for Appalachian Studies and Services. (2018a). Center for Appalachian studies and services. Retrieved from https://www.etsu.edu/cas/cass/

Center for Appalachian Studies and Services. (2018b). Appalachian teaching project. Retrieved from https://www.etsu.edu/cas/cass/projects/

City of Johnson City. (2017). FY 2016 Annual report Johnson City, Tennessee. Retrieved from http: / / www.johnsoncitytn.org/uploads/files/cr/2016\%20Annual\%20Report.pdf

Daniels, C., Fox, H., Poindexter, S.-J., \& Reilly, E. (2015). Saving all the freaks on the life raft: Blending documentation strategy with community engagement to build a local music archives. American Archivist, 78(1), 238-261.

East Tennessee State University. (2017a). East Tennessee State University strategic plan 20162026. Retrieved from https: //www.etsu.edu/president/documents/univ_strategicplan.pdf

East Tennessee State University. (2017b). ETSU mission, vision, values. Retrieved from https://www.etsu.edu/president/mission.php

East Tennessee State University, Department of Appalachian Studies. (n.d.). Courses. Retrieved from https: //www.etsu.edu/cas/das/gradcertificate/courses.php

East Tennessee State University, Office of University Relations. (2016, January 19). Longawaited multicultural center open at ETSU. Retrieved from https://www.etsu.edu/news/2016/01_jan/mc_center_opens.aspx

East Tennessee State University, Office of University Relations. (2017, October 20). 'A New Subjectivity' exhibition looks at Expressionism in new way. Retrieved from 
https://www.etsu.edu/news/2017/10-oct/nr_mbm_new_subjectivity.aspx

East Tennessee State University, Office of University Relations. (2018, January 10). 'Finite Disappointment/Infinite Hope' exhibit at Reece commemorates King, Civil Rights. Retrieved from https://www.etsu.edu/news/2018/01-jan/nr_reece_kifle_gediyon.aspx

East Tennessee State University, University Governance. (2015). Service-learning/community and public service standing committee. Retrieved from https://www.etsu.edu/universitygovernance/governancecommittees /servicelearning.php

East Tennessee State University, University Governance. (2018). Governance organizations. Retrieved from https://www.etsu.edu/universitygovernance/governanceorg.php

Greene, M. A. (2014). Into the deep end: One archivist's struggles with diversity, community, collaboration and their implications for the profession. In M. A. Caldera, \& K. M. Neal (Eds.), Through the Archival Looking Glass: A Reader on Diversity and Inclusion (pp. 23-60). Chicago, IL: Society of American Archivists.

Grimm, T. B., \& Noriega, C. A. (2013). Documenting regional Latino arts and culture: Case studies for a collaborative, community-oriented approach. American Archivist, 76(1), 95-112.

Herrin, R. (2009). Documenting community traditions: Marketing the craftspeople and artists of Northeast Tennessee. Retrieved from

https://www.etsu.edu/cas/cass/projects/documents/projectetsu/etsu_final_report_2009.pdf

Herrin, R. (2011). Documenting community traditions: Sustainable agriculture in northeast Tennessee. Retrieved from https://www.etsu.edu/cas/cass/projects/documents/projectetsu/atp_2011_etsu_final_report.pdf

Herrin, R. (2015). Documenting community traditions: Railroad history and cultural heritage tourism in northeast Tennessee. Retrieved from https://www.etsu.edu/cas/cass/projects/documents/projectetsu/2014_atp_etsu_final_report.pdf

Mehra, B., \& Davis, R. (2015). A strategic diversity manifesto for public libraries in the 21st century. New Library World, 116(1/2), 15-36.

Noland, B. (2016, October 3). ETSU state of the university address. Retrieved from https://www.etsu.edu/president/documents/state_of_etsu_2016.pdf

Noland, B. (2017). Rocky Fork state park: Linking natural and economic resources through oral histories and community engagement. Retrieved from https://www.etsu.edu/cas/cass/projects/documents/documents /2017_etsu_proposal.pdf

Peterson, M. D. (2018). Welcome. Retrieved from City of Johnson City: http://www.johnsoncitytn.org/ 
Poole, A. H. (2017). Pinkett's charges: Recruiting, retaining, and mentoring archivists of color in the twenty-first century. American Archivist, 80(1), 103-134.

Ramirez, M. H. (2015). Being assumed not to be: A critique of whiteness as an archival imperative. American Archivist, 78(2), 339-356.

Roach, R. (2018). Welcome. Retrieved from https://www.etsu.edu/cas/das/welcome.php

Society of American Archivists. (2011). SAA core values statement and code of ethics. Retrieved from https://www2.archivists.org/statements/saa-core-values-statement-and-code-ofethics

Taylor, C. (2017). Getting our house in order: Moving from diversity to inclusion. American Archivist, 80(1), 19-29.

Tennessee Higher Education Commission. (2018). Centers of excellence and emphasis. Retrieved from https: / / www.tn.gov/thec/bureaus/academic-affairs-and-studentsuccess/academic-programs/chairs-and-centers-of-excellence/redirect-chairs-andcenters-of-excellence/centers-of-excellence-and-emphasis.html

U.S. Census Bureau. (2010). Johnson City city, Tennessee. Retrieved from https://factfinder.census.gov/bkmk/cf/1.0/en/place/Johnson City city, Tennessee/POPULATION/DECENNIAL_CNT

White, K. L., \& Gilliland, A. J. (2010). Promoting reflexivity and inclusivity in archival education, research, and practice. The Library Quarterly, 80(3), 231-248.

Laura E. Smith (smithle1@etsu.edu) is the Education \& Outreach Archivist at East Tennessee State University's Archives of Appalachia. She received Bachelor of Arts degrees in U.S. History and Film Studies from The Ohio State University. She holds a Master of Library Science degree with a specialization in Archives and Records Management and a Master of Arts degree in History from Indiana University. She is a continuing education student at the University of Tennessee furthering her professional interests in diversity and inclusion and archival accessibility. 